\title{
Primary dystonia, DYT4 type
}

INSERM

\section{Source}

INSERM. (1999). Orphanet: an online rare disease and orphan drug data base. Primary dystonia, DYT 4 type. ORPHA:98805

DYT 4 type primary dystonia is characterized by predominantly laryngeal dystonia (manifesting as whispering dysphonia) and cervical dystonia (manifesting as torticollis). 